\title{
An Algorithm for Converting Color Images to Monochromatic Hatched Images*
}

\author{
Hideo KASAI**
}

\begin{abstract}
At present inserting color images into articles or reports is too expensive. It is useful if the color image can be converted automatically to monochromatic image on the CRT screen. Therefore, an algorithm for converting a color image to a monochromatic image with the hatch on the CRT display has been developed. This paper reports the conversion algorithm and program written in $\mathrm{C}$ language. This converted monochromatic image can be made into a hard copy with an dot-impact printer, and this image can be inserted into articles or reports.
\end{abstract}

Key Words: Image processing, Algorithm, GVRAM, LANDSAT

\section{Introduction}

A color printer is necessary to make a hard copy of a color image on the CRT display. At the present time, inserting color images into articles or reports are too expensive. For example, pseudo color images of LANDSAT are needed to print by full color. If the color image can be converted to a monochromatic hatched image on the CRT disaplay, it is possible to copy this image with a monochromatic dot-impact printer without a decrease in precision, and it is convenient to insert color images into articles or reports.

This paper presents an algorithm to convert from a color image to a monochromatic image using the hatch on the CRT display.

\section{The principle and the algorithm for the conversion}

The image displayed on the CRT screen is the monitor of GVRAM (Graphic Video Random Acsses Memory) (Fig. 1). The image on the CRT screen is composed of pixels. Those pixels coincide with the screen coordinate on the CRT screen. Therefore, in order to process the image displayed on the CRT screen, an access to the GVRAM is needed.

In order to convert a color image to the monochromatic hatched image, first the boundary lines between colors must be drawn. Because the boundaries are the

* Presented at the Geoinforum'-94 (Osaka)

** Yamanashi Gakuin University, Sakaori 2-4-5, Kofu, Yamanashi 400, Japan

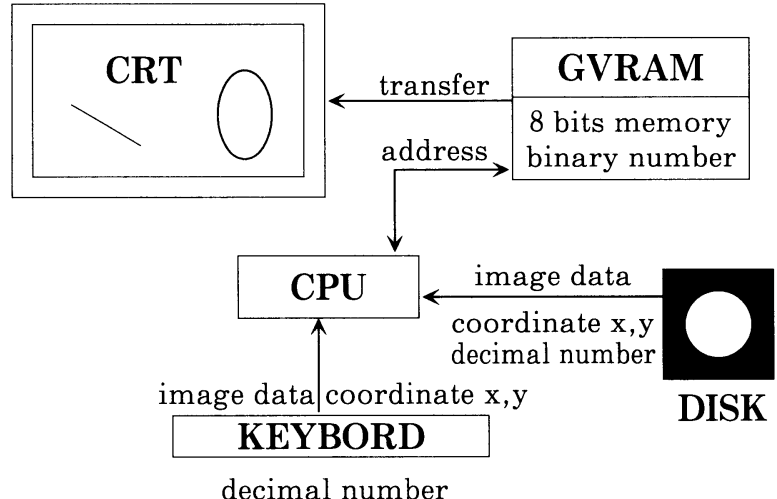

Fig. 1 The relation between GVRAM and CRT screen. Graphic coordinate input from the keyboard or disk unit are converted to address on the GVRAM, and the data input from these input equipment are converted to binary number by CPU.

changing point of displayed colors, the difference of the values of the adjacent two points (pixels), $d_{n}$ is examined as follows:

$$
d_{n}=p_{i}-p_{i+1}
$$

Where, $p_{i}$ and $p_{i+1}$ are the values of $i$ th and $i+1$ th pixels respectively, and subscripts $i$ and $i+1$ represent locations of pixel respectively. This paper defines the value of pixels as the color number of each pixel. If the value of $d_{n}$ is 0 , the value of both points (pixels) are the same, 
therefore, the boundary does not exist in this location. On the contrary, if the value of $d_{n}$ is not 0 , the boundary exists in this location. The white dot is displayed on the CRT screen to represent the boundary on this location.

The horizontal scan ( $x$ direction) and the vertical scan ( $y$ direction) are executed to find the boundary as follows:

$$
\begin{array}{ll}
\text { horizontal scan } & d_{n h}=p(x-1, \mathrm{y})-p(x, y) \\
\text { vertical scan } & d_{n v}=p(x, y-1)-p(x, y)
\end{array}
$$

Where, $d_{n h}$ indicates the difference in the $x$ direction. The $d_{n v}$ indicates the differences of $y$ direction. $P(x, y)$ is the value of the pixel. The $x$ and $y$ are the coordinate values of pixel. The horizontal scan changes the value of $x$ from 0 (original point) to 639 ( $\max$ value) fixing the value of $y$ (the value of $y$ is 0 at first). If the value of $x$ exceeds 639 , the value of $y$ is added to 1 and the value of $x$ returns to 0 , and the scan is repeated. The vertical scan changes the value of $y$ from 0 to 399 ( $\max$ value) on the condition that the value of $x$ (the value of $x$ is 0 at first) is fixed.

The use of the function which read the value of the pixel $(x, y)$ as the color number (for example, Turbo C) permits the algorithm to simply be a one for detecting boundaries. If this function is not equipped, this function is written as follows (Kasai, 1994):

(1) By the equation(4), off set address AD of GVRAM corresponding to the coordinate $(x, y)$ of the pixel is calculated.

$$
A D=\operatorname{int}(x / 8)+y \times 80
$$

Where, the origin of this coordinate is $(0,0)$. "int" is the function which turns the result of th operation $x / 8$ into an integer.

(2) Read the memory contents of four GVRAM.

$$
\begin{aligned}
& \mathrm{sgb}=\& \text { HA800 }: \mathrm{d}_{1}=\operatorname{peek}(\mathrm{AD}+\mathrm{sgb}) \cdots \text { GVRAM0 (blue) } \\
& \operatorname{sgb}=\& \text { HB000 }: \mathrm{d}_{2}=\operatorname{peek}(\mathrm{AD}+\mathrm{sgb}) \cdots \text { GVRAM1 (red) } \\
& \mathrm{sgb}=\& \text { HB800 }: \mathrm{d}_{3}=\text { peek }(A D+\mathrm{sgb}) \cdots \text { GVRAM2 (green) } \\
& \operatorname{sgb}=\& \text { HE000 }: d_{4}=\operatorname{peek}(A D+\operatorname{sgb}) \cdots \text { GVRAM3 (brightness) }
\end{aligned}
$$

Where, $\mathrm{d}_{1}, \mathrm{~d}_{2}, \mathrm{~d}_{3}$ and $\mathrm{d}_{4}$ are memory contents of GVRAM respectively, and "peek" is the memory read function. Variable "sgb" is the segment base of each GVRAM. The value \&HA800, \& HB000, \& HE000 and
\&HB800 are the segment base of GVRAM respectively for NEC PC9801 series (NEC, 1985), and symbole \&H is of hexadecimal notation.

(3) GVRAM is the eight bit memory, so the bit position $l c$ corresponding to $x$ is calculated by equation (6). This bit position is counted from the left side of the bit row.

$$
l c=\bmod (x, 8)
$$

Here, "mod" is the function which calculates the remainder of the division $x / 8$.

(4) The value of the pixels of four GVRAM are calculated the equation (7) as the binary digit.

$$
\left.\begin{array}{ll}
\mathrm{b}_{1}=\mathrm{d}_{1} & \text { AND cb }(l c) \cdots \text { GVRAM0 (blue) } \\
\mathrm{b}_{2}=\mathrm{d}_{2} & \text { AND cb }(l c) \cdots \text { GVRAM1 (red) } \\
\mathrm{b}_{3}=\mathrm{d}_{3} & \text { AND cb }(l c) \cdots \text { GVRAM2 (green) } \\
\mathrm{b}_{4}=\mathrm{d}_{4} & \text { AND cb }(l c) \cdots \cdot \text { GVRAM3 (brightness) }
\end{array}\right\}
$$

Where, $b_{1}, b_{2}, b_{3}$ and $b_{4}$ are the value of pixels of GVRAM respectively, and "AND" is the bitwise logical product. Arrangement $\mathrm{cb}(l c)$ is the check bit row to pick up the value of pixels. Because GVRAM is an eight bit memory, the value of the check bit row is as follows:

$$
\begin{aligned}
& \mathrm{cb}(0)=\& H 80, \mathrm{cb}(1)=\& \mathrm{H} 40, \mathrm{cb}(2)=\& \mathrm{H} 20, \mathrm{cb}(3)=\& \mathrm{H} 10 \\
& \mathrm{cb}(4)=\& H 08, \mathrm{cb}(5)=\& \mathrm{H} 04, \mathrm{cb}(6)=\& \mathrm{H} 02, \mathrm{cb}(7)=\& \mathrm{H} 08
\end{aligned}
$$

By the overlay of the three primary colors of light and the brightness of light, colors are displayed on the CRT screen. Therfore, it is possible to inspect the color of point $(x, y)$ by the examination of the condition of the overlay as shown in Table 1 . For example, if $d_{1}$ is 1 and the rest are all 0 , the displayed color is blue. If $\mathrm{d}_{2}$ and $\mathrm{d}_{3}$ are both 1 and $\mathrm{d}_{1}$ and $\mathrm{d}_{3}$ are both 0 , the displayed color is brown.

As mentioned above, the locations displayed in white color are boundaries. However, because the boundary is the changing point of colors, the boundary point is not on the CRT screen. Therefore, white dots are displayed on either side (pixel) of this point on the CRT screen to display boundary lines. If dots in white are dotted on both sides of this point, boundary lines on the CRT screen become thick (width of the line is 2 dots). In this case, the boundary lines are drawn on the edge of each color. On the detailed image, these thick lines 
Table 1 The overlay of four planes and displayed color. 0 is nonactive and 1 is active. If only blue plane is active, blue color is displayed on the CRT screen.

\begin{tabular}{|l|c|c|c|c|}
\hline \multicolumn{1}{|c|}{ color } & blue & red & green & bright \\
\hline black & 0 & 0 & 0 & 0 \\
blue & 1 & 0 & 0 & 0 \\
green & 0 & 0 & 1 & 0 \\
cyan & 1 & 0 & 1 & 0 \\
red & 0 & 1 & 0 & 0 \\
magenta & 1 & 1 & 0 & 0 \\
brown & 0 & 1 & 1 & 0 \\
lightgray & 1 & 1 & 1 & 0 \\
darkgray & 0 & 0 & 0 & 1 \\
lightblue & 1 & 0 & 0 & 1 \\
lightgreen & 0 & 0 & 1 & 1 \\
lightcyan & 1 & 0 & 1 & 1 \\
lightred & 0 & 1 & 0 & 1 \\
lightmagenta & 0 & 1 & 0 & 1 \\
yellow & 1 & 1 & 0 & 1 \\
white & 1 & 1 & 1 & 1 \\
\hline
\end{tabular}

frequently cause illegibility. Otherwise, if white dots are dotted on either side, boundary lines become thin (width of the line is $1 \mathrm{dot}$ ). Converted images become illegible. Fig. 2 represents the images of thick boundary line, and Fig. 3 represents the image of thin boundary lines. As illustrated in Fig. 4, the white circles are dotted on right side or lower side of the boundary.

After boundary lines are drawn, the interior is painted by using the hatch. The location of painting is found by the horizontal scan only. Painting with a hatch is executed with every color. If the value of pixel $(x, y)$ is identical with the specified color number, (for example, color number is 1 ), the paint command is executed on the condition that the starting point of painting is the $(x, y)$ point and that boundary color is white.

The algorithm for conversion is shown in Fig. 5, and this program written in $\mathrm{C}$ language is listed in appendix.

\section{To make a legible image}

The image converted from the detailed color image frequently became illegible. Isolated points become black by this conversion causing illegibillity. Therefore, before the conversion to monochromatic image, it is better to make a legible image even though the information of the image reduces. If the isolated points and thin line disappeares from the color image, the converted image becomes legible.

The manner of disappearance of isolated points is as follows (Fig. 6).

(1) Read the color numbers of the point $(x, y)$ on the CRT screen.

(2) Read the color numbers of eight neighbors of point $(x, y)$.

(3) The color number of the point $(x, y)$ changes by the following rule.

(a) If the color numbers of eight neighbors are all the same (color number is $k$ ), and the color number of the point $(x, y)$ is not $k$, the color number of the point $(x$, $y$ ) is changed to $k$ (Fig. $6 \mathrm{~A}$ ).

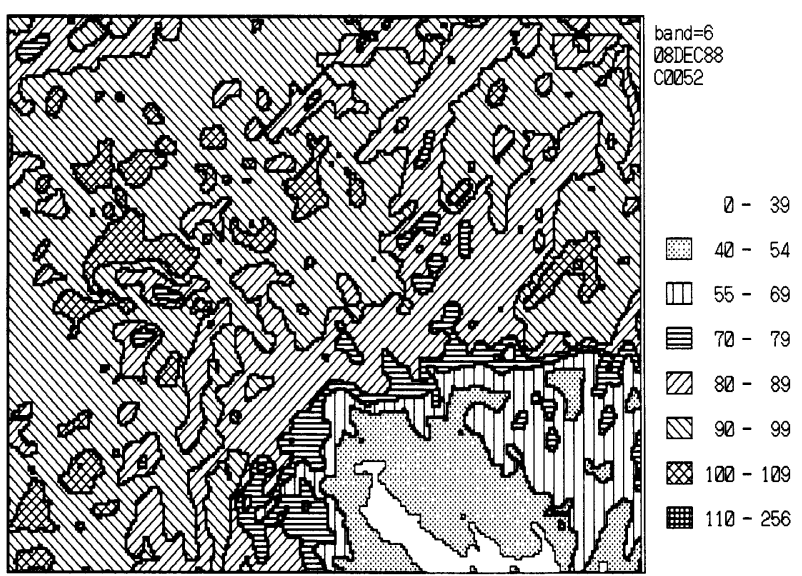

Fig. 2 The result of the conversion.

Boundary lines are thick. This image is converted from a psuedo color image of LANDSAT 5 (band 6) around Mt. Fuji, Japan. Numbers present the slice level.

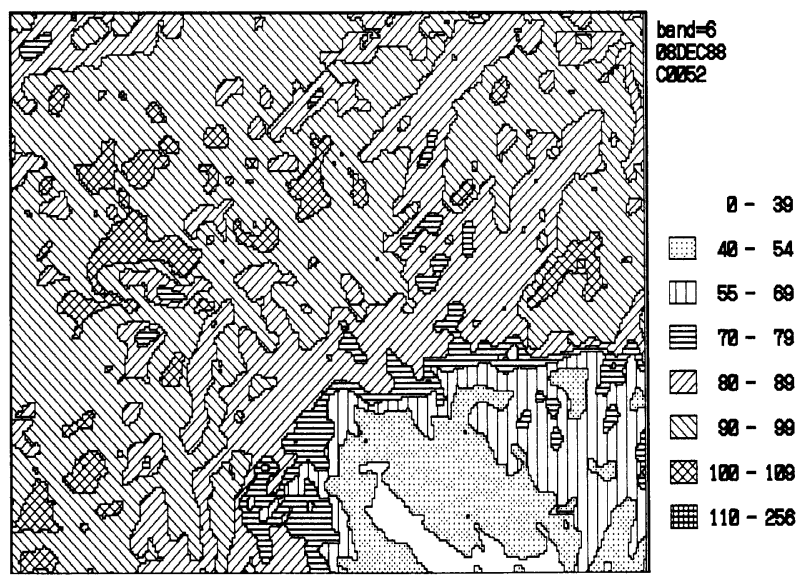

Fig. 3 The result of the conversion. Boundary lines are thin. This image is converted from a psuedo color image of LANDSAT 5 (band 6) around Mt. Fuji, Japan. Numbers present the slice level. 


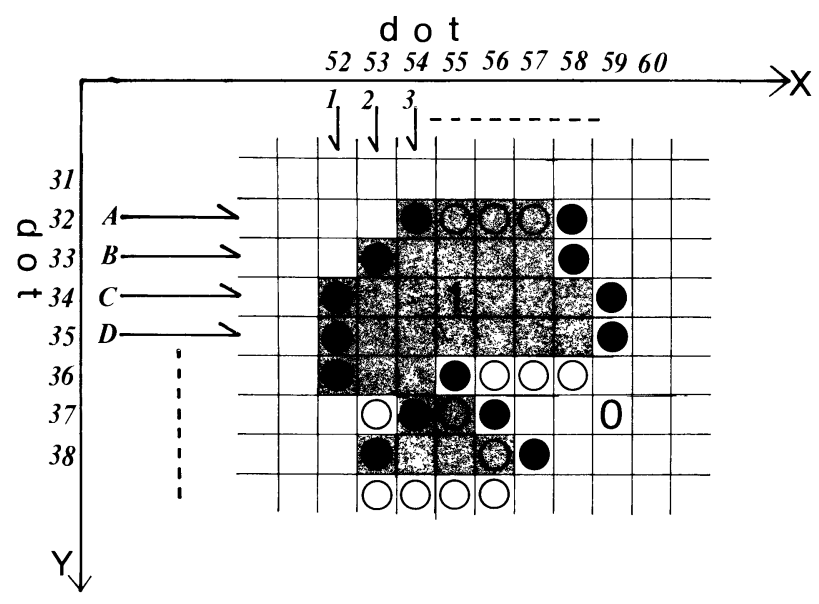

Fig. 4 Detect the outline of the binary image.

Open circles are the boundary points detected by the vertical scan only, solid circles are the boundary points detected either by the vertical scan or by the horizontal scan. The vertical scan is performed in the order of $1,2,3, \cdots$, and the horizontal scan is performed in the order of $\mathrm{A}$, $\mathrm{B}, \mathrm{C} \cdots$.

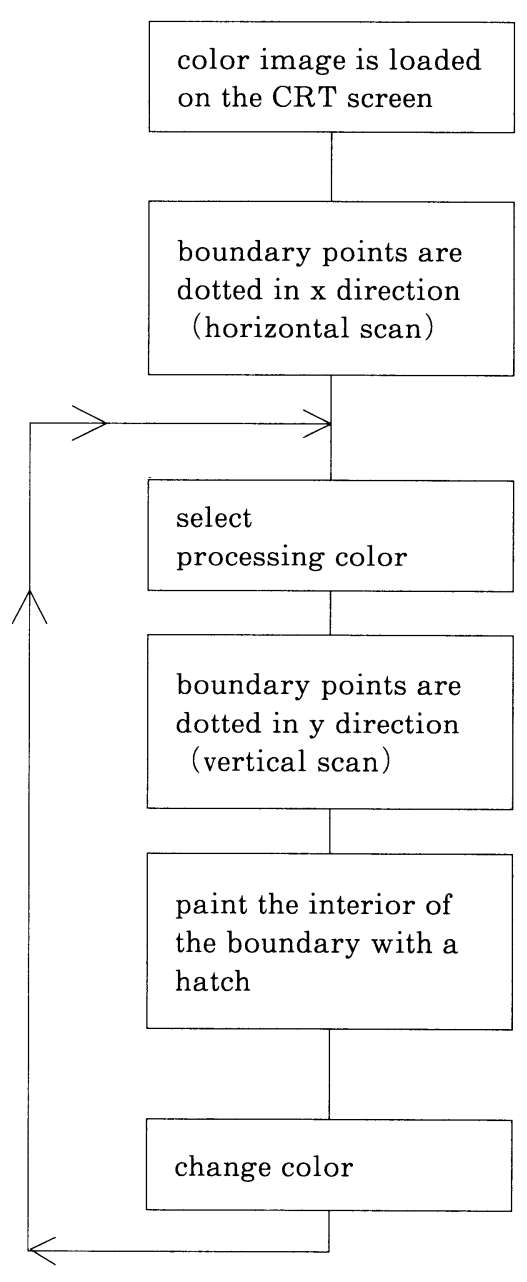

Fig. 5 The algorithm for the conversion.

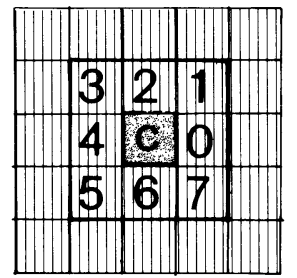

A

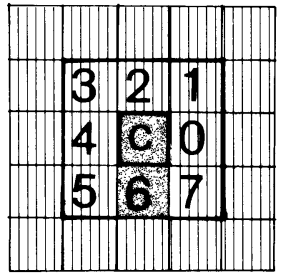

B
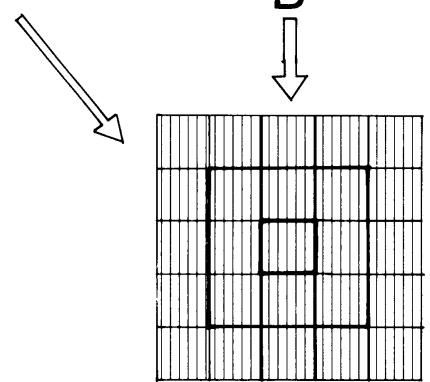

$\mathrm{R}$

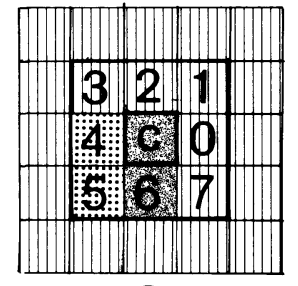

C

Fig. 6 The principle of removing isolated point. 
(b) If the color numbers of seven points of neighbors are the same ( color number is $k$ ) and the color number of the point $(x, y)$ and the rest one are not $\mathrm{k}$, the color number of the point $(x, y)$ and the other one are changed to $k$ (Fig. $6 \mathrm{~B}$ ).

(c) If the color numbers of the neighbor points are classfied into some group, the most frequent color number is used as the color number of the point $(x, y)$ and eight neighbors (Fig. $6 \mathrm{C}$ ).

The result of this pocess is shown in Fig. 7. The upper image in Fig. 7 is the converted figure, and the lower one in Fig. 7 is the result of this process. Open circles of upper are isolated points, that were removed.

This pre-processing permits the image to be legible. But, for the very detailed image, there is a restriction in the application of this pre-processing.

\section{Concluding Remarks}

The algorithm permits conversion to monochromatic hatched images from color images on the CRT screen. The program listed in appendix performed the conversion in a few minutes. Further. when the function which paints the interior of boundary lines with a hatch - "area_paint" - is removed from this program, only boudary lines are displayed.

\section{Acknowledgments}

The author is thankfull to Associate Professer Charles Randle Allala of Yamanashi Gakuin University for helpfull suggestions.

\section{Reference}

Kasai H. (1994) Image Processing with the Image Scanner (1), Geoinformatics, 5, 21-38 (in Japanese) NEC (1985) PC9801 VF2/VM0/VM2 USERS MANUAL, $306 \mathrm{p}$ (in Japanese)
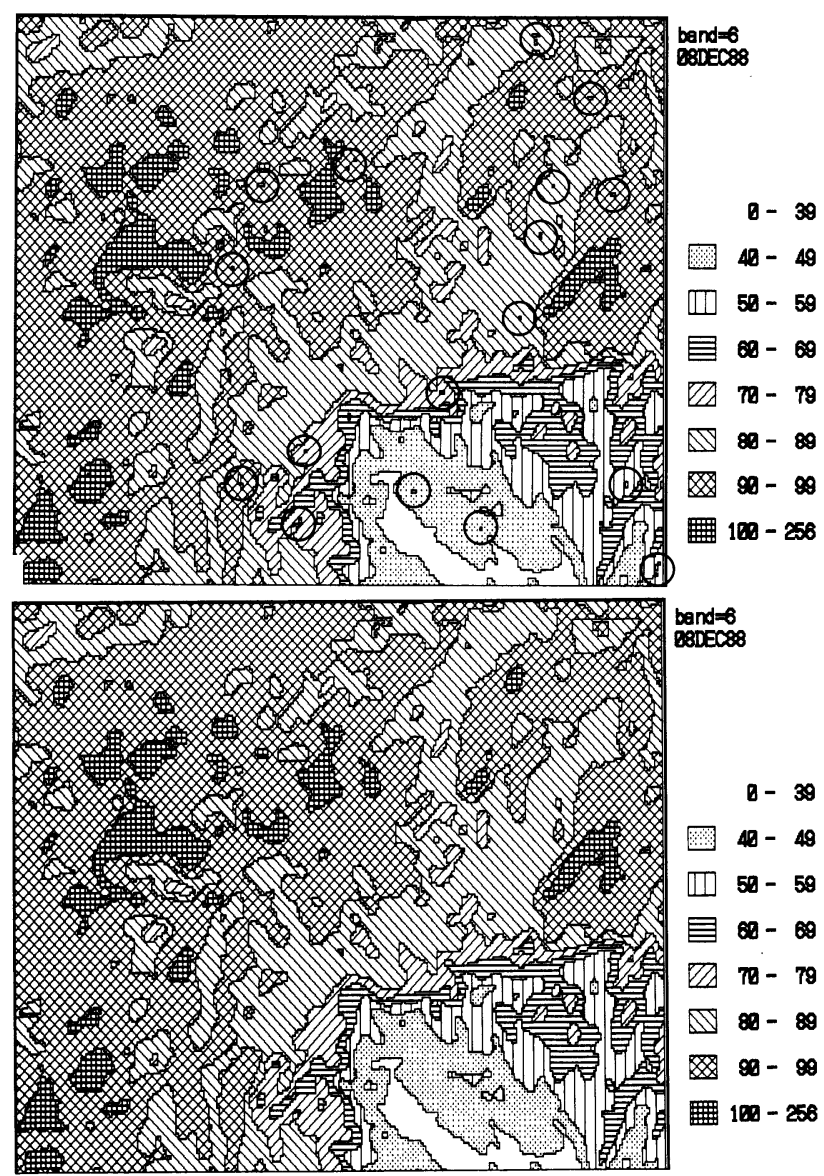

Fig. 7 The result of removing isolated point. This image is converted from a psuedo color image of LANDSAT 5 (band 6) around Mt. Fuji, Japan. Numbers present the slice level. 
要 旨

カラー画像からハッチを使用した白黒画像への変換アルゴリズム

現在, カラー画像を論文や報告書に掲載することは費用が高くつく．カラー画像を C R T 上で自動的に白黒画像に 変換できれば便利である．このため，C R T上でカラー画像をハッチを用いた白黒画像に変換するアルゴリズムが開 発された．本文ではこの変換アルゴリズムとプログラム（C 言語）について報告する.この変換された画像はドット インパクトプリンターでハードコピーをとることができ，この変換された画像や論文や報告書に掲載することができ る.

キーワード：画像処理，アルゴリズム，GVRAM，ランドサット

\section{(Program List)}

Appendix

$/ * * * * * * * * * * * * * * * * * * * * * * * * * /$
$/ * * *$ Convert color image $* * /$
$/ * * *$ to monochromatic image with the hatch $* * /$
$/ * * *$ Turbo $\mathrm{C}$
$/ * * * * * * * * * * * * * * * * * * * * * * * * * /$

\# include "graphics.h"

\# include "stdio.h"

void area_paint(int);

void $\mathrm{cm}$ convert(int);

void det_mergin(void);

void main(void)

char gname[50]; /*file name of image file* /

int $\mathrm{j} ; \quad / *$ control variable*/

int flag; $\quad / *$ mode flag $(0: 8$ colors $1: 16 \operatorname{col} l o s) * /$

int gerr;

int gdriver;

int gmode;

$/ * *$ Initialize */

flag $=1 ; \quad / *$ set mode flag $* /$

gdriver =DETECT; gmode=PC98C16;

initgraph(\&gdriver,\&gmode,"”);

if $($ (gerr= graphresult ()$) !=$ grok $)$

printf("error:\%s¥n",grapherrormsg(gerr));

exit(1);

for $(j=0 ; j<16 ; j++)\{$ setpalette $(j, j) ;\}$

cleardevice();clrscr();
（1995年 5 月 8 日受付，1995年11月10日受理）

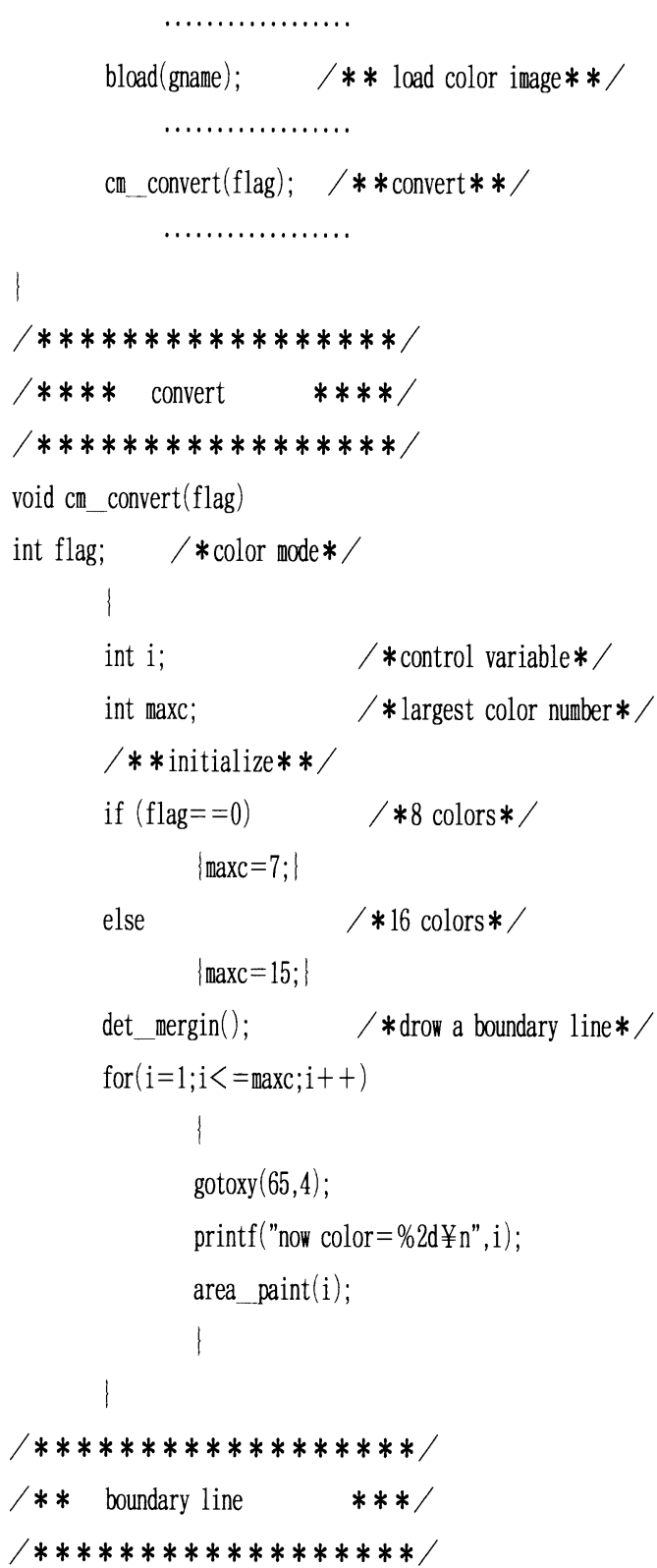

void det_mergin(void) 


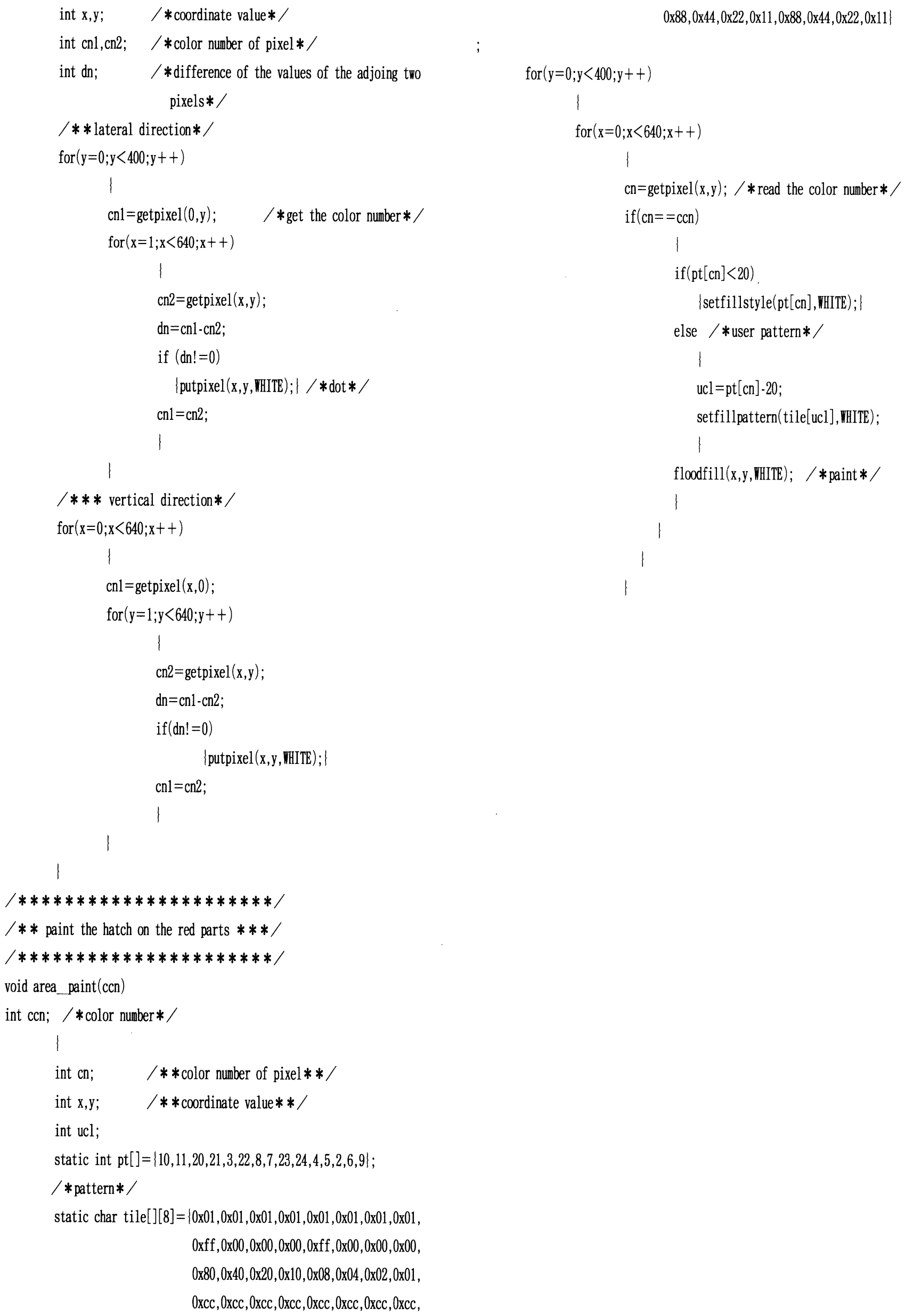

